\title{
Effect of Feeding Corn, Hull-Less or Hulled Barley on Fermentation by Mixed Cultures of Ruminal Microorganisms
}

\author{
V. Fellner, ${ }^{\star 1}$ J. C. Burns, ${ }^{*} \dagger$ and D. S. Marshall* $¥$ \\ *Department of Animal Science, North Carolina State University, Raleigh 27695 \\ †Department of Crop Science and USDA/ARS, Raleigh, NC 27695 \\ ‡Department of Plant Pathology and USDA/ARS, Raleigh, NC 27695
}

\section{ABSTRACT}

Increased demands for corn grain warrant the evaluation of alternative grain types for ruminant production systems. This study was conducted to determine the effects of hulled and hull-less barley (Hordeum vulgare L.) cultivars compared with corn (Zea mays L.) as an alternative grain type on fermentation in cultures of mixed ruminal microorganisms. Three continuous fermentors were fed $14 \mathrm{~g}$ of dry feed per day (divided equally between 2 feedings) consisting of alfalfa (Medicago sativa L.) hay pellets (40\% of dry matter) and 1) ground corn, 2) hulled barley, or 3) hull-less barley concentrate ( $60 \%$ of dry matter) in each fermentor. Following an adaptation period of $5 \mathrm{~d}$, culture samples were taken at $2 \mathrm{~h}$ after the morning feeding on $\mathrm{d} 6,7$, and 8 of each period for analysis. A second run of the fermentors followed the same treatment sequence to provide replication. Culture $\mathrm{pH}$ was reduced with corn (5.55) and did not differ between barley cultivars (average $\mathrm{pH}$ 5.89). Total volatile fatty acid concentration and acetate to propionate ratio were not different across grain type or barley cultivar with the exception of greater total volatile fatty acid concentrations with hull-less barley. Corn produced less methane (14.6 $\mathrm{mmol} / \mathrm{d})$ and ammonia-N (7.3 mg/100 mL) compared with barley $(33.1 \mathrm{mmol} / \mathrm{d}$ and $22 \mathrm{mg} / 100 \mathrm{~mL}$, respectively); methane was greater with hull-less barley but ammonia-N concentration was similar between the 2 barley cultivars. Hull-less barley had greater digestibility compared with hulled barley, and corn had reduced digestibility compared with barley. Concentrations of C18:0 were greater and those of C18:1 and C18:2 lesser in cultures fed hulled and hull-less barley compared with corn. Our data indicate that grain type and barley cultivar have an impact on ruminal fermentation. The

Received February 5, 2007.

Accepted February 1, 2008.

${ }^{1}$ Corresponding author: Vivek_Fellner@ncsu.edu lesser starch concentration of barley minimized the drop in culture $\mathrm{pH}$ and improved digestibility.

Key words: barley, corn, ruminal fermentation

\section{INTRODUCTION}

Grains are supplemented in the ration as a source of starch to meet energy needs of ruminants. Excess starch consumption could be detrimental to ruminal fermentation with a negative impact on animal performance. On the other hand, reducing the amount of starch fermented in the rumen may reduce microbial protein synthesis. Barley contains less starch (65\%) than corn $(72 \%$; Waldo, 1973) but the proportion fermented in the rumen is greater than that of corn (Herrera-Saldana et al., 1990). Enhanced synchrony of energy and nitrogen release because of the greater ruminal degradation of starch and CP of barley grain has been implicated in improved animal performance (Rotger et al., 2006). Others have shown no benefit of feeding barley over corn on milk production (Casper et al., 1990) or weight gain (Zinn et al., 1996). Removing the hull increases the digestible energy content of the diet (Zinn et al., 1996); however, limited data on feeding hull-less varieties have shown a modest improvement, if any, on digestibility when compared with hulled barley or corn (Zinn et al., 1996; Yang et al., 1997). Nutritional characteristics of barley grain can vary significantly across cultivars (Boss and Bowman, 1996; Bowman et al., 2001) and much of this variability is attributed to the fiber components of the hull and the starch quality of the endosperm (Izydorczyk et al., 2000). Amylolytic bacteria are the primary fermenters of starch in the rumen. However, there is evidence to suggest that the type of cereal grain may affect the relative ability of amylolytic species to ferment starch that is released from barley vs. that released from corn (McAllister et al., 1990). Few studies have evaluated the fermentation characteristics of hull-less and hulled barley when compared with corn. This study was conducted to assess the fermentation efficiency of hulled vs. hull-less barley cultivars and to compare barley with 
corn in cultures of mixed ruminal microorganisms. Another objective was to monitor ruminal lipid profiles as affected by grain type and barley cultivars.

\section{MATERIALS AND METHODS}

\section{Fermentor Conditions}

Whole ruminal contents were taken from a ruminally fistulated cow fed a forage diet, transported in vacuum containers to the lab, and filtered through double-layered cheesecloth before incubation in the fermentors. Approximately $700 \mathrm{~mL}$ of the strained ruminal fluid was transferred into each of the 3 fermentors. Culture vessels ( $1 \mathrm{~L}$ total capacity) used in this study were allglass closed systems with a continuous independent flow of liquid and particulate matter. The fermentors allow for a natural stratification of their contents with the aid of a glass ' $\mathrm{T}$ ' that served as the fermentor overflow positioned near the bottom of the suspended particle phase. A continuous flow of $\mathrm{CO}_{2}(20 \mathrm{~mL} / \mathrm{min})$ maintained anaerobic conditions as well as a positive internal pressure in the fermentors. Artificial saliva (Slyter et al., 1966) was delivered using a precision pump set at a flow rate of $0.73 \mathrm{~mL} / \mathrm{min}$ resulting in a fractional dilution rate of $6.8 \% / \mathrm{h}$ (Eun et al., 2004b). The temperature of ruminal cultures was maintained at $39^{\circ} \mathrm{C}$ by a circulating water bath and a central paddle was set at a speed of $10 \mathrm{rpm}$ to continuously mix the ruminal cultures. Operation of the fermentors was according to procedures previously outlined (Fellner et al., 1995). This study was approved by the North Carolina State University Institution of Animal Care and Use Committee.

\section{Diets and Experimental Design}

A total of $14 \mathrm{~g}$ of feed (DM basis) was placed in each fermentor daily in 2 equal portions at 0800 and 1500 h. Diets consisted of a 60:40 concentrate mix and alfalfa pellets. The concentrate mix included corn, hull-less barley, or hulled barley, soybean meal $(49 \% \mathrm{CP})$, and a vitamin and mineral premix (Table 1). Three diets were formulated to vary in the source of starch using corn (ground), hulled barley, or hull-less barley (cracked) as the grain source. The fatty acid (FA) content of alfalfa hay was $2.2 \%$ and that of soybean oil was $88.1 \%$. The soybean oil consisted predominantly of C18:2 (55\%) and C18:1 cis (22.5\%). The fat in hullless and hulled barley also consisted primarily of C18:2 (55\%) and C18:1 cis (18\%). Corn had similar levels of C18:2 (50\%) but slightly greater levels of C18:1 cis (32\%) compared with the other grains. The concentration of C18:3 was much greater in both the hulled and hullless barley $(6 \%)$ than in corn $(1 \%)$.
Table 1. Ingredients and chemical composition of total mixed diets

\begin{tabular}{lccc}
\hline & \multicolumn{3}{c}{ Diet } \\
\cline { 2 - 3 } & \multicolumn{2}{c}{ Barley } \\
\cline { 2 - 3 } Item & Hulled $^{1}$ & Hull-less $^{2}$ & Corn \\
\hline Ingredient composition, \% of DM & & & \\
Hulled & 48 & - & - \\
Hull-less & - & 48 & - \\
Corn & - & - & 48 \\
SBM (49\%) & 10.8 & 10.8 & 10.8 \\
Premix & 1.2 & 1.2 & 1.2 \\
Alfalfa (pellets) & 40 & 40 & 40 \\
Nutrient composition, \% & & & \\
DM & 88.4 & 88.1 & 90.8 \\
OM & 90.8 & 92.0 & 92.0 \\
NDF & 38.9 & 37.9 & 28.6 \\
ADF & 21.2 & 18.4 & 17.6 \\
CP & 19.8 & 18.7 & 17.4 \\
\hline
\end{tabular}

${ }^{1}$ Cultivar 'Mollybloom' (PI 564593).

${ }^{2}$ Cultivar 'Doyce' (PI 634932).

${ }^{3}$ Consisted of $0.8 \%$ limestone; $0.4 \%$ salt; $0.09 \%$ magnesium oxide; $0.68 \%$ sodium bicarbonate; $0.06 \%$ potassium chloride and $0.12 \%$ vitamin trace mineral mix which provided, per kilogram of diet: $66 \mathrm{mg}$ of S, $46 \mathrm{mg}$ of $\mathrm{Zn}, 46 \mathrm{mg}$ of Mn, $14 \mathrm{mg}$ of $\mathrm{Cu}, 11.6 \mathrm{mg}$ of Fe, $0.8 \mathrm{mg}$ of I, $0.7 \mathrm{mg}$ of $\mathrm{Co}, 0.3 \mathrm{mg}$ of Se, 7,075 IU of vitamin A, 1,769 IU of vitamin D, and 21 IU of vitamin E.

All dietary ingredients were weighed and mixed with the respective grain sources before being placed in bags and stored in the refrigerator. The corn and the hulled or hull-less barley diets were randomly assigned to a fermentor in a randomized complete block design. Fermentors were allowed a 5-d adaptation period followed by $3 \mathrm{~d}$ of data collection. All diets were fermented twice so that this study utilized 3 continuous culture fermentors on 2 separate 8 -d runs.

\section{Sample Collection and Analytical Procedures}

Feed samples were analyzed for DM, ash, and nitrogen according to the methods of the AOAC (1999). Total $\mathrm{N}$ was multiplied by 6.25 to determine CP. Neutral detergent fiber and $\mathrm{ADF}$ were analyzed using an Ankom 200 fiber extractor (Ankom Technologies, Fairport, NY) according to the procedure described by Van Soest et al. (1991). Feed lipid was extracted as outlined by Fellner et al. (1995). Five milliliters of thoroughly mixed culture content was collected $2 \mathrm{~h}$ after feeding twice daily, centrifuged at $10,000 \times g$ for $10 \mathrm{~min}$, and the supernatant was analyzed for VFA by GLC (model CP3380, Varian, Walnut Creek, CA) and for $\mathrm{NH}_{3}-\mathrm{N}$ using a colorimetric assay (Beecher and Whitten, 1970). Ten microliters of headspace gas from the fermentor was drawn into a gas-tight syringe (Hamilton Co., Reno, NV) $2 \mathrm{~h}$ after feeding and analyzed for methane using GLC. Daily methane output ( $\mathrm{mmol} / \mathrm{d}$ ) was calculated as reported previously (Jenkins et al., 2003). The $\mathrm{pH}$ 
of ruminal cultures was recorded when samples were taken for methane analysis. Separate 5-mL samples of the mixed culture contents were taken at $2 \mathrm{~h}$ after the morning feeding and frozen $\left(-70^{\circ} \mathrm{C}\right)$ for long-chain $\mathrm{FA}$ analysis. The frozen samples were thawed, methylated (Kramer et al., 1997), and then analyzed for long-chain FA by GLC. Fatty acid methyl esters were separated on a $100-\mathrm{m} \times 0.25-\mathrm{mm} \times 0.2-\mu \mathrm{m}$ film thickness fusedsilica capillary column (SP-2560, Supelco, Bellefonte, PA). Verification of peak identity was established by comparison of peak retention times to known standards.

On the last day of each run the entire contents of the fermentors were saved. Homogeneous aliquots were used to determine fermentor DM. Microbial cells were isolated by differential centrifugation according to the procedure outlined by Bauchart et al.(1990). Contents were first centrifuged at $1,074 \times g$ for $5 \mathrm{~min}$ to precipitate particles and then at $47,800 \times g$ for $20 \mathrm{~min}$ to sediment the bacteria. The resulting microbial pellet was dried for $4 \mathrm{~h}$ at $50^{\circ} \mathrm{C}$ and analyzed for microbial $\mathrm{N}$ concentrations.

Apparent digestibility was calculated based on the amount of substrate fermented to VFA and methane and true digestibility was estimated by accounting for the microbial biomass (Eun et al., 2004a,b).

Data were analyzed as a randomized complete block design using the Proc Mixed procedure of SAS (SAS Institute, 1999). Fermentation variables were analyzed as repeated measures with the treatments being the source of variation in the model. Preplanned orthogonal contrasts were used to detect differences among treatment means. Comparisons made were 1) corn vs. barley and 2) hulled barley vs. hull-less barley.

\section{RESULTS AND DISCUSSION}

The CP content of the total diets was slightly greater for the barley diets compared with corn (Table 1). Because of the lesser protein content of the hull-less barley and corn (Table 2), soybean meal and alfalfa accounted for a greater proportion of the total CP in those diets. The FA profile (Table 2) showed that the concentration of C18:1 cis was greater and that of C18:3 lesser in corn than in the 2 barley types. Compared with corn, barley had no effect $(P<0.11)$ on total VFA concentration and acetate:propionate $(\mathrm{A}: \mathrm{P})$ ratio but increased $(P<0.01)$ $\mathrm{pH}$ (Table 3). Barley also increased $(P<0.01)$ acetate, isobutyrate, and valerate and reduced $(P<0.02)$ butyrate and isovalerate without affecting propionate (Table 3). In another in vitro study, ground barley increased total VFA concentration without affecting $\mathrm{pH}$ or A:P ratio when compared with corn (Jenkins et al., 2003). Feeding either high or low barley supplements in
Table 2. Characteristics of corn and barley grains

\begin{tabular}{lrrr}
\hline & \multicolumn{3}{c}{ Diet } \\
\cline { 2 - 3 } & \multicolumn{2}{c}{ Barley } \\
\cline { 2 - 3 } Item & 86.3 & 85.8 & Corn \\
\cline { 2 - 3 } Hulled & Hull-less $^{2}$ & 90.3 \\
DM, \% & & & \\
Nutrient content, \% of DM & 93.9 & 96.4 & 96.5 \\
OM & 31.0 & 28.8 & 9.0 \\
NDF & 10.6 & 4.5 & 3.0 \\
ADF & 14.5 & 12.4 & 9.5 \\
CP & & & \\
Fatty acids, \% of total & 19.6 & 19.6 & 13.9 \\
C16:0 & 1.4 & 1.2 & 2.2 \\
C18:0 & 17.4 & 18.8 & 31.9 \\
C18:1 cis & 55.7 & 54.7 & 50.4 \\
C18:2 & 0.0 & 0.2 & 0.4 \\
C20:0 & 5.9 & 5.5 & 1.1 \\
C18:3 & & \\
\hline
\end{tabular}

${ }^{1}$ Cultivar 'Mollybloom' (PI 564593).

${ }^{2}$ Cultivar 'Doyce' (PI 634932).

a forage-based diet to lactating cows tended to increase total VFA concentrations without affecting $\mathrm{pH}$ or A:P ratio (Feng et al., 1995). Yang et al. (1997) fed steamrolled barley as a concentrate in a barley silage-based diet and reported greater total VFA without any change in $\mathrm{pH}$ and $\mathrm{A}: \mathrm{P}$ ratio when compared with cows fed similar diets with corn. Steers fed 3 different varieties of barley had greater VFA concentration and A:P ratio but significantly reduced ruminal $\mathrm{pH}$ when compared with corn (Boss and Bowman, 1996). Several factors may contribute to differences in response to feeding barley vs. corn. Both the variation in the nutrient content among grains as well as particle size may play a significant role (Hunt, 1996). In the present study, the 2 barley cultivars provided a greater proportion of total fiber compared with corn.

Hull-less barley increased $(P<0.01)$ total VFA concentrations and reduced valerate concentration, but had no effect on ruminal $\mathrm{pH}$ or A:P ratio (Table 3). The lack of a $\mathrm{pH}$ effect was unexpected because the hull (which consists mainly of cellulose, hemicellulose, lignin, and pectin) is the major contributor of fiber in barley grain. The hull-less barley used in our diets did have a lower ADF content but had very similar NDF compared with the hulled barley.

Although caution is needed when comparing in vitro with in vivo results, steers fed rolled hull-less barley had similar ruminal $\mathrm{pH}$ when compared with either corn or rolled hulled barley despite greater concentrations of ruminal propionate (Zinn et al., 1996).

Barley increased $(P<0.01)$ total methane production and ammonia concentrations in ruminal cultures compared with corn (Table 3). Ammonia concentration averaged $22 \mathrm{mg} / 100 \mathrm{~mL}$ of culture contents and was not significantly different between the 2 barley cultivars, 
Table 3. Effect of diets containing corn (C) and barley (B) [(hulled (HD) and hull-less (HS)] on VFA, methane, $\mathrm{pH}$ and ammonia- $\mathrm{N}$ in mixed cultures of ruminal microorganisms

\begin{tabular}{|c|c|c|c|c|c|c|}
\hline \multirow[b]{3}{*}{ Item } & \multicolumn{3}{|c|}{ Treatment } & \multirow[b]{3}{*}{$\mathrm{SE}$} & \multirow{2}{*}{\multicolumn{2}{|c|}{ Contrast }} \\
\hline & \multicolumn{2}{|c|}{ Barley } & \multirow[b]{2}{*}{ Corn } & & & \\
\hline & Hulled & Hull-less & & & C vs. B & HD vs. HS \\
\hline Total VFA, mM & 45.79 & 51.11 & 45.77 & 3.41 & 0.11 & 0.01 \\
\hline Individual VFA, mol/100 mol & & & & & & \\
\hline Acetate (A) & 48.43 & 46.63 & 41.78 & 1.18 & 0.01 & 0.25 \\
\hline Propionate $(\mathrm{P})$ & 26.88 & 28.55 & 26.42 & 1.27 & 0.42 & 0.36 \\
\hline Isobutyrate & 1.08 & 1.12 & 0.48 & 0.05 & 0.01 & 0.38 \\
\hline Butyrate & 15.05 & 16.65 & 23.81 & 1.69 & 0.01 & 0.38 \\
\hline Isovalerate & 3.68 & 3.28 & 4.42 & 0.39 & 0.02 & 0.37 \\
\hline Valerate & 4.99 & 3.77 & 3.11 & 0.45 & 0.03 & 0.07 \\
\hline $\mathrm{A}: \mathrm{P}$ & 1.82 & 1.64 & 1.64 & 0.09 & 0.42 & 0.18 \\
\hline Methane, $\mathrm{mmol} / \mathrm{d}$ & 30.7 & 35.4 & 14.6 & 1.20 & 0.01 & 0.01 \\
\hline Culture $\mathrm{pH}$ & 5.90 & 5.87 & 5.55 & 0.05 & 0.01 & 0.14 \\
\hline $\mathrm{NH}_{3}-\mathrm{N}, \mathrm{mg} / 100 \mathrm{~mL}$ & 21.8 & 22.26 & 7.3 & 1.57 & 0.01 & 0.83 \\
\hline
\end{tabular}

but hull-less barley resulted in greater $(P<0.01)$ methane production. The increase in methane and ammonia as a result of feeding barley vs. corn is similar to results reported from other in vitro cultures (Jenkins et al., 2003; Rotger et al., 2006) as well as from feedlot cattle (Feng et al., 1995). Given the similar culture $\mathrm{pH}$ and lower fiber content the increase in methane with the hull-less barley was unexpected. The lesser ammonia$\mathrm{N}$ concentration in cultures fed corn (Table 3) resulted in less $(P<0.01)$ daily outflow of ammonia-N compared with barley (Table 4$)$.

Feeding corn increased $(P<0.01)$ the concentration of $\mathrm{N}$ in microbial cells when compared with barley (Table 4). Apparent DM digestibility was lesser $(P<0.03)$ for corn compared with barley due primarily to a significantly greater digestibility with the hull-less cultivar as opposed to the hulled (Table 4).

Source of grain, but not barley cultivar, had an effect on the biohydrogenation of FA (Table 5). Barley increased $(P<0.01)$ the proportion of $\mathrm{C} 16: 0$ and $\mathrm{C} 18: 0$ compared with corn. The concentrations of $\mathrm{C} 18: 1$ trans and cis isomers and C18:2, however, were greater $(P<$ $0.01)$ in cultures fed corn than in those fed barley. Total C18:3 remained unaffected by grain source or barley type. In a previous study (Jenkins et al., 2003), increased levels of C18:1 and C18:2 were also reported for corn compared with barley. Concentration of C18:1 in corn grain (Table 2) was greater (31.9\%) compared with that in barley (18.1\%), which may explain the increase in C18:1. However, C18:2 concentrations were similar in corn and the 2 barley cultivars (50.4 and $55.2 \%$ of total FA, respectively). Barley more than doubled the C18:0 concentration in cultures and reduced the level of C18:2, which is indicative of enhanced biohydrogenation. Corn-based diets, however, lowered culture $\mathrm{pH}$, which can limit lipolysis, a prerequisite step for biohydrogenation (Van Nevel and Demeyer, 1996).

We found significant differences in the fermentation pattern between the 2 grain types as well as between the 2 barley cultivars. Concentrates are included in rations primarily as an energy source (NRC, 2001) but increased starch fermentation can result in adverse ef-

Table 4. Effect of diets containing corn (C) and barley (B) [(hulled (HD) and hull-less (HS)] on microbial $\mathrm{N}$, microbial efficiency, $\mathrm{N}$ flow, and digestibility in mixed cultures of ruminal microorganisms

\begin{tabular}{|c|c|c|c|c|c|c|}
\hline \multirow[b]{3}{*}{ Item } & \multicolumn{3}{|c|}{ Treatment } & \multirow[b]{3}{*}{$\mathrm{SE}$} & & \\
\hline & \multicolumn{2}{|c|}{ Barley } & \multirow[b]{2}{*}{ Corn } & & \multicolumn{2}{|c|}{ Contrast } \\
\hline & Hulled & Hull-less & & & $\mathrm{C}$ vs. $\mathrm{B}$ & HD vs. HS \\
\hline Microbial cells, g/d & 0.35 & 0.28 & 0.26 & 05 & 0.37 & 0.37 \\
\hline Microbial N, \% & 8.61 & 8.37 & 9.59 & 0.11 & 0.01 & 0.21 \\
\hline Ammonia-N, g/d & 0.23 & 0.23 & 0.08 & 0.02 & 0.01 & 0.83 \\
\hline \multicolumn{7}{|l|}{ Digestibility, \% } \\
\hline Apparent ${ }^{1}$ & 39.0 & 45.0 & 35.1 & 2.19 & 0.03 & 0.02 \\
\hline True $^{2}$ & 41.3 & 47.1 & 37.5 & 3.36 & 0.09 & 0.29 \\
\hline
\end{tabular}


Table 5. Effect of diets containing corn (C) and barley (B) [(hulled (HD) and hull-less (HS)] on biohydrogenation of long-chain fatty acids (LCFA) in mixed cultures of ruminal microorganisms

\begin{tabular}{|c|c|c|c|c|c|c|}
\hline \multirow[b]{3}{*}{ LCFA } & \multicolumn{3}{|c|}{ Treatment } & \multirow[b]{3}{*}{$\mathrm{SE}$} & \multirow{2}{*}{\multicolumn{2}{|c|}{ Contrast }} \\
\hline & \multicolumn{2}{|c|}{ Barley } & \multirow[b]{2}{*}{ Corn } & & & \\
\hline & Hulled & Hull-less & & & C vs. B & HD vs. HS \\
\hline & 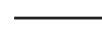 & $\%$ of total & - & & & \\
\hline C16:0 & 24.75 & 25.17 & 20.66 & 0.75 & 0.01 & 0.70 \\
\hline C18:0 & 47.45 & 48.51 & 22.56 & 2.46 & 0.01 & 0.75 \\
\hline $\mathrm{C} 18: 1$ trans & 6.87 & 5.96 & 18.74 & 2.47 & 0.01 & 0.69 \\
\hline $\mathrm{C} 18: 1 \mathrm{cis}$ & 6.12 & 6.25 & 18.71 & 0.95 & 0.01 & 0.93 \\
\hline C18:2 & 3.81 & 4.18 & 16.86 & 2.21 & 0.01 & 0.89 \\
\hline C18:3 & 0.70 & 0.59 & 0.91 & 0.15 & 0.27 & 0.52 \\
\hline
\end{tabular}

fects in the rumen. One factor commonly identified as having a negative impact on rumen function with highenergy diets is $\mathrm{pH}$ (Mertens, 1977; Russell et al., 1979). Reduced $\mathrm{pH}$ is associated with a decline in cellulolytic activity and subsequent decrease in digestibility. Data from this study indicate that reductions in ruminal $\mathrm{pH}$ may differ between grains and may not always reduce $\mathrm{DM}$ digestion. The reduced $\mathrm{pH}$ with corn did lower apparent DM digestibility compared with barley, whereas hull-less barley improved apparent DM digestion despite having a $\mathrm{pH}$ similar to the hulled barley. In some instances $\mathrm{pH}$ may be a primary factor in reducing DM digestibility, but apparently additional mechanisms are operating as suggested by others (Caton and Dhuyvetter, 1997).

Although grains are included in rations to provide energy, it is well known that the starch and CP concentration between barley and corn, as well as within barley cultivars, can vary extensively (Hunt, 1996; Izydorczyk et al., 2000; Bowman et al., 2001). Barley is assigned a lesser energy value compared with corn because of its reduced starch concentration, but the extent of barley starch degradation in the rumen is greater than that of corn. An increase in starch digestion in the rumen can potentially result in an improvement in the protein status compared with corn that has less ruminally degradable starch. The improved protein status would occur as a result of increased microbial protein via increased OM fermentation. Energy availability from barley may also be affected by the digestibility of its fiber fraction. The degradability of barley is correlated with its hull percentage (Hunt, 1996) and may explain the reduced digestibility of the hulled variety fed in the present study.

Feeding corn reduced ammonia concentration; however, it seems unlikely that dietary $\mathrm{N}$ was limiting in this study (Satter and Slyter, 1974). With greater starch availability and greater ammonia concentration one would expect a better synchrony of carbon and nitrogen with barley. Hull-less barley had less fiber and greater apparent digestibility compared with hulled barley. The starch and CP matrix among cereal grains are not the same, and patterns of amylolytic digestion on maize starch granules have been shown to differ from those of barley (McAllister et al., 1990). The major amylolytic species, Ruminobacter amylophilus, Butyrivibrio fibrisolvens, and Streptococcus bovis, are capable of digesting the protein matrix of barley and not maize, and $B$. fibrisolvens have a greater proteolytic and deaminative activity resulting in greater ammonia concentration over the other 2 amylolytic species (McAllister et al., 1990).

\section{CONCLUSIONS}

Barley-based diets can provide similar or more fermentable energy in the rumen compared with cornbased diets. Diet digestibility was improved with barley compared with corn, with hull-less barley resulting in greater energy yields and overall digestibility. Providing barley at $48 \%$ of diet DM was equal or superior to corn as an energy source. In addition to $\mathrm{pH}$, other factors that affect microbial digestion and ruminal fermentation exist in the rumen, particularly when different grain sources are included in the diet. Compositional data among barley cultivars reported in the literature and differences in fermentation characteristics between barley cultivars reported here mandate the necessity of cultivar designation and inclusion of their chemical profile to permit valid comparisons of animal responses among barley trials.

\section{ACKNOWLEDGMENTS}

The authors want to thank Sarah Jo McLeod (Dept. Anim. Sci., North Carolina State University) for her technical assistance. Approved as technical contribution of the North Carolina Agricultural Research Station, North Carolina State University. Additional support was provided by North Carolina Crop Improvement Foundation. 


\section{REFERENCES}

AOAC. 1999. Official Methods of Analysis. 16th ed. AOAC, Arlington, VA.

Bauchart, D., F. Legay-Carmier, M. Doreau, and B. Gaillard. 1990. Lipid metabolism of liquid-associated and solid-adherent bacteria in rumen contents of dairy cows offered lipid-supplemented diets. Br. J. Nutr. 63:563-578.

Beecher, G. R., and B. K. Whitten. 1970. Ammonia determination: Reagent modification and interfering compounds. Anal. Biochem. 36:243-246.

Boss, D. L., and J. G. P. Bowman. 1996. Barley varieties for finishing steers: II. Ruminal characteristics and rate, site, and extent of digestion. J. Anim. Sci. 74:1973-1981.

Bowman, J. G. P., T. K. Blake, L. M. M. Surber, D. K. Habernicht, and H. Bockelman. 2001. Feed-quality variation in the barley core collection of the USDA National Small Grains Collection. Crop Sci. 41:863-870.

Casper, D. P., D. J. Schingoethe, and W. A. Eisenbeisz. 1990. Response of early lactation dairy cows fed diets varying in source of nonstructural carbohydrate and crude protein. J. Dairy Sci. 73:1039-1050.

Caton, J. S., and D. V. Dhuyvetter. 1997. Influence of energy supplementation on grazing ruminants. Requirements and Responses. J. Anim. Sci. 75:533-542.

Eun, J.-S., V. Fellner, J. C. Burns, and M. L. Gumpertz. 2004b. Fermentation of eastern gamagrass (Tripsacum dactyloides [L.] L.) by mixed cultures of ruminal microorganisms with or without supplemental corn. J. Anim. Sci. 82:170-178.

Eun, J.-S., V. Fellner, and M. L. Gumpertz. 2004a. Methane production by mixed ruminal cultures incubated in dual-flow fermentors. J. Dairy Sci. 87:112-121.

Fellner, V., F. D. Sauer, and J. K. G. Kramer. 1995. Steady-state rates of linoleic acid biohydrogenation by ruminal bacteria in continuous culture. J. Dairy Sci. 78:1815-1823.

Feng, P., C. W. Hunt, G. T. Pritchard, and S. M. Parish. 1995. Effect of barley variety and dietary barley content on digestive function in beef steers fed grass hay-based diets. J. Anim. Sci. 73:34763484.

Herrera-Saldana, R., R. Gomez-alarcon, M. Torabi, and J. T. Huber. 1990. Influence of synchronizing protein and starch degradation in the rumen on nutrient utilization and microbial synthesis. J. Dairy Sci. 73:142-148.

Hunt, C. W. 1996. Factors affecting the feeding quality of barley for ruminants. Anim. Feed Sci. Technol. 62:37-48.

Izydorczyk, M. S., J. Storsley, D. Labossiere, A. W. MacGregor, and B. G. Rossnagel. 2000. Variation in total and soluble $\beta$-glucan content in hulless barley: Effects of thermal, physical, and enzymic treatments. J. Agric. Food Chem. 48:982-989.
Jenkins, T. C., V. Fellner, and R. K. McGuffey. 2003. Monensin by fat interactions on trans FAs in cultures of mixed ruminal microbes grown in continuous fermentors fed corn or barley. J. Dairy Sci. 86:324-330.

Kramer, J. K. G., V. Fellner, M. E. R. Dugan, F. D. Sauer, M. M. Mossoba, and M. P. Yurawecz. 1997. Evaluating acid and base catalysts in the methylation of milk and rumen FA with special emphasis on conjugated dienes and total trans FA. Lipids 32:1219-1228.

McAllister, T. A., K.-J. Cheng, L. M. Rode, and C. W. Forsberg. 1990. Digestion of barley, maize, and wheat by selected species of ruminal bacteria. Appl. Environ. Microbiol. 56:3146-3153.

Mertens, D. R. 1977. Dietary fiber components: Relationship to the rate and extent of ruminal digestion. Fed. Proc. 36:187-192.

NRC. 2001. Nutrient Requirements of Dairy Cattle. 7th ed. National Academy Press, Washington, DC

Rotger, A., A. Ferret, S. Calsamiglia, and X. Manteca. 2006. Effects of nonstructural carbohydrates and protein sources on intake, apparent total tract digestibility, and ruminal metabolism in vivo and in vitro with high-concentrate beef cattle diets. J. Anim. Sci. 84:1188-1196.

Russell, J. B., W. M. Sharp, and R. L. Baldwin. 1979. The effect of $\mathrm{pH}$ on maximum bacterial growth rate and its possible role as a determinant of bacterial competition in the rumen. J. Anim. Sci. 48:251-255.

SAS Institute. 1999. SAS System for Windows. Version 8. SAS Inst., Inc., Cary, NC.

Satter, L. D., and L. L. Slyter. 1974. Effect on ammonia concentration on ruminal microbial protein production in vivo. Br. J. Nutr. 32:199-208

Slyter, L. L., M. P. Bryant, and M. J. Wolin. 1966. Effect of $\mathrm{pH}$ on population and fermentation in a continuously cultured rumen ecosystem. Appl. Microbiol. 14:573-577.

Van Nevel, C. J., and D. I. Demeyer. 1996. Influence of $\mathrm{pH}$ on lipolysis and biohydrogenation of soybean oil by rumen contents in vitro. Reprod. Nutr. Dev. 36:53-65.

Van Soest, P. J., J. B. Robertson, and B. A. Lewis. 1991. Methods for dietary fiber, neutral detergent fiber and non-starch polysaccharides in relation to animal nutrition. J. Dairy Sci. 74:35833597.

Waldo, D. R. 1973. Extent and partition of cereal grain starch digestion in ruminants. J. Anim. Sci. 37:1062-1074.

Yang, W. Z., K. A. Beauchemin, K. M. Koenig, and L. M. Rode. 1997. Comparison of hull-less barley, barley, or corn for lactating cows: Effects on extent of digestion and milk production. J. Dairy Sci. 80:2475-2486.

Zinn, R. A., M. Montano, and Y. Shen. 1996. Comparative feeding value of hull-less vs covered barley for feedlot cattle. J. Anim. Sci. 74:1187-1193. 